\title{
DOES MATERNAL THYROID AUTOIMMUNITY PREDICT ADVERSE PREGNANCY OUTCOMES?
}

J. Sastre-Marcos ${ }^{1}$, F. Val-Zaballos ${ }^{1}$, MA. Ruiz-Gines², M. Olivar-Azuara1 ${ }^{1}$, M. Agudo-Mazacaga ${ }^{2}$, R. Fontelles-Alcover², D. Maldonado ${ }^{3}$, J. LopezLopez ${ }^{1}$

${ }^{1}$ Endocrinology. ${ }^{2}$ Biochemistry. ${ }^{3}$ Obstetrics. Hospital Virgen de la Salud, Complejo Hospitalario de Toledo. Spain.

\section{Background}

Previous studies of association between maternal thyroid autoimmunity and adverse pregnancy outcomes have produced inconsistent results. First trimester for chromosomal anomalies is routine in our center and provides an opportunity to test thyroid function and thyroid autoimmunity.

\section{Objective}

To examine whether thyroid autoimmunity detected at first trimester screening is predictive of a range of adverse obstetric and fetal outcomes.

\section{Patients and methods}

We studied 438 women with singleton pregnancies who underwent first trimester screening test between June and July 2014 . 33 women $(7,5 \%)$ were excluded because of previous thyroid disease.

$>$ Women were eligible if fetal gestational age was 10-14 weeks from ultrasound crown-rump length measurement.

$>$ We evaluated the association between thyroid autoimmunity [positive TPO and/or Tiroglobulin (TG) antibodies] with:

1.- Thyroid function: TSH, free T4.

2.- Adverse obstetric outcomes: pregnancy loss after 20 weeks, pre-eclampsia, cesarean section, preterm birth.

3.- Adverse neonatal outcomes: small size for gestational age (SGA), metabolic complications, birth defects and neonatal death.

\section{Results}

\section{Figure 1:}

Women with thyroid autoimmunity

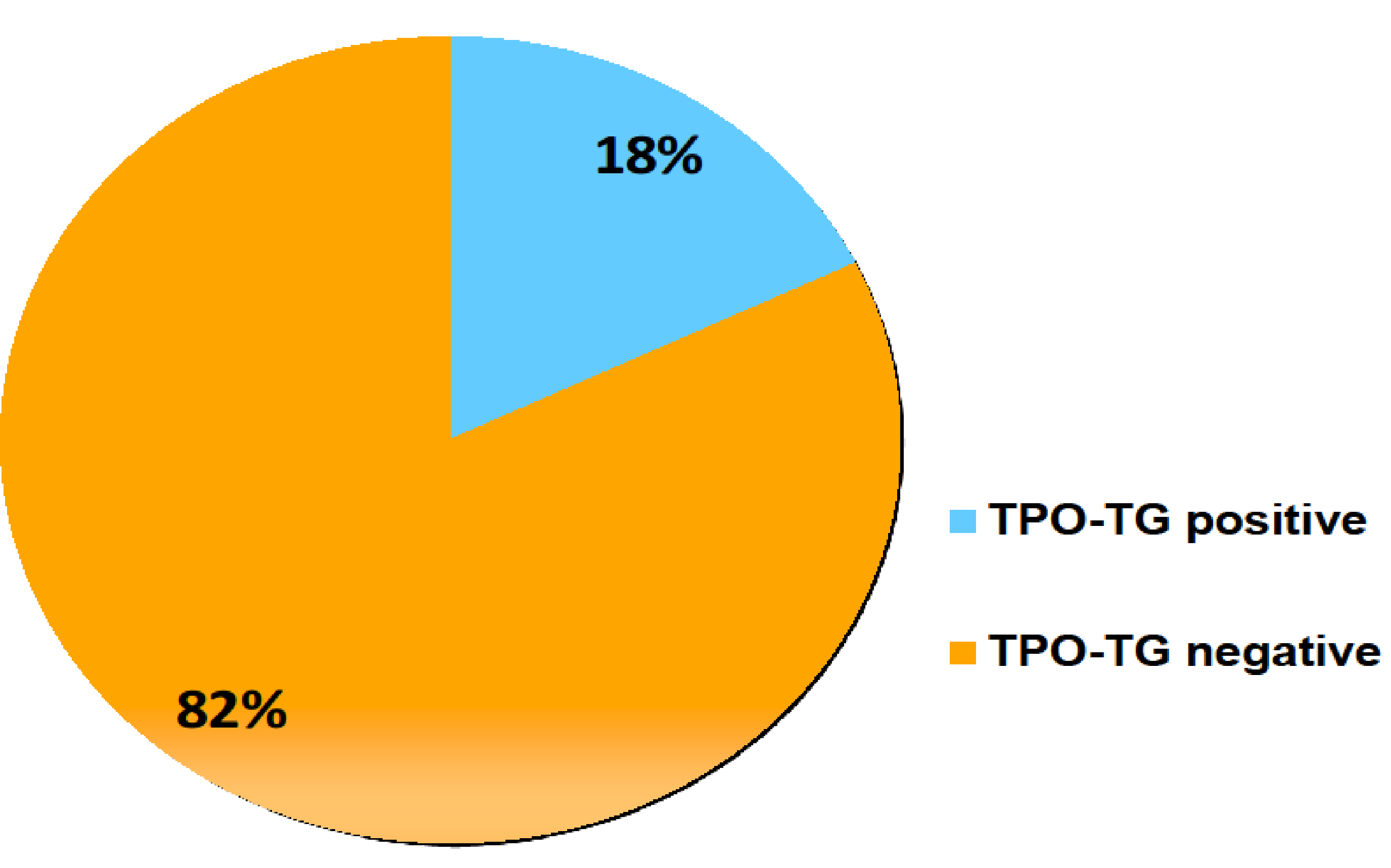

\section{Table 3:}

Adverse neonatal outcomes

\begin{tabular}{|l}
\hline Birth weigth $(\mathrm{kg})$ \\
\hline Male sex (\%) \\
\hline SGA $(\%)$ \\
\hline $\begin{array}{l}\text { Metabolic } \\
\text { complications (\%) }\end{array}$ \\
\hline Neonatal deaths (\%) \\
\hline Birth defects (\%) \\
\hline $\begin{array}{l}\text { Any neonatal } \\
\text { complication (\%) }\end{array}$ \\
\hline
\end{tabular}

TPO-TG positive TPO-TG negative $p$ value $3,4(2,6-3,6)$

54,4

7,5

14,2

0,0

1,8

29,8

\section{Conclusions}

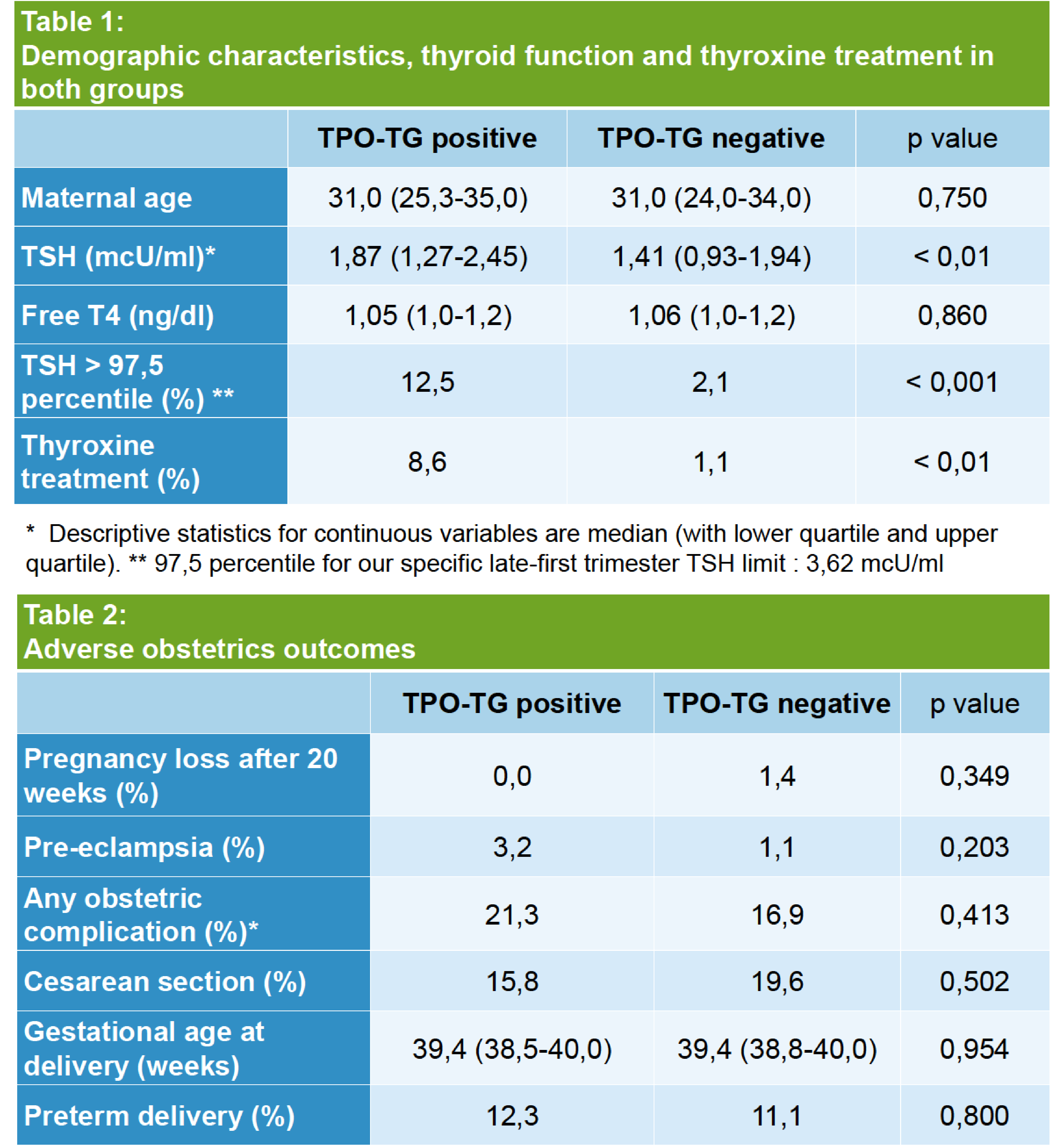

${ }^{*}$ Comprises: pregnancy loss, placenta previa, hypertension, g.diabetes, cesarean s. or preterm d

Thyroid autoimmunity provides higher risk for mild abnormalities in thyroid function but does not predict adverse obstetrics and neonatal outcomes in our cohort. 